\title{
WORKING METHOD TO ENHANCE END-USER VALUE FOR AGING-IN-PLACE
}

\author{
F.J.M. van Gassel \\ Eindhoven University of Technology, The Netherlands \\ f.j.m.v.gassel@tue.nl \\ J.E.M.H. van Bronswijk \\ Eindhoven University of Technology, The Netherlands \\ j.e.m.h.v.bronswijk@tue.nl
}

\begin{abstract}
We focus on finding the appropriate working method to enhance end-user value for aging-inplace. Older adults prefer to stay in their own environment and enjoy remaining independent and socially integrated. However, our current built environment is largely unsuitable for Aging-in-Place. The objective of this research is to test a working method for analyzing ADL (Activities of Daily Living), and to automate, robotize or mechanize those that are problematic. Novice designers (MSc students in Architecture and Building Services) analyzed an ADL by observation, and formulated observed problems and their elements. Secondly the students designed methodically an improvement. Thirdly, the newly designed solution was validated in an expert discussion. It appeared that by developing new concepts in a systematic way, end-user value gets in focus and is enhanced. This research gives more insight in teaching a symbiotic society where robotic application and human beings share the same sphere of living.
\end{abstract}

KEYWORDS: teaching novice experts, user values, aging-in-place

\section{INTRODUCTION}

Aging-in-Place is an accepted concept in our graying society. Older adults prefer to stay in their own environment and enjoy remaining independent and taking part in societal and other social activities. In short, they strive at full citizenship: physically, mentally and socially. However, our current built environment is commonly not suitable for Aging-in-Place. Think, for instance, of shopping independently but with a walker.

ADL (Activities of Daily Living) and iADL (instrumental Activities of Daily Living) have been categorized and scales were developed to assess older adults' needs and capabilities.

Katz et al (1970) describe six basic activities of daily living: bathing, dressing, toileting, moving in and out of bed and chair, continence and feeding, while Lawton (1969) mentioned eight instrumental activities ability to use a telephone, shopping, food preparation, housekeeping, laundry, mode of transportation, responsibility for own medication, and ability to handle finances.

Robotics and home automation equipment in the broadest sense can support and improve daily living. The performance is improved of activities such as cleaning the house, going up 
and down the stairs, preparing a meal, keeping rooms comfortable and clean, and entertaining people. This is especially true when muscle and brainpower decline.

In a Dutch study by the Rathenau Instituut (Lau et al, 2009) the researchers "noted that most research efforts and funding seem to be focused on the very high-tech end of the robotics scale". A more user-oriented and multi-disciplinary approach is required to enhance the public demand.

By an evaluation of 13 projects Franchimon (2009 p17) came to the conclusion that the needs of the users were hardly considered in the application of personal alarm systems, videophones or burglar alarm systems. He concluded that these applications must be offer by demanddriven needs.

Nowadays new technologies such as robots and home equipment are becoming largely available. In order to use these technologies successfully, it is essential to have a good understanding of the activities of daily living. Using a valid and suitable working method can help to get this understanding.

Van Bronswijk (2009) distinguishes four ages: $1^{\text {st }}$ Age Youth (education), $2^{\text {nd }}$ Age Adulthood (work for income and family formation), $3^{\text {rd }}$ Age Older Adulthood (active retirement) and the $4^{\text {th }}$ Age Elderly (frailty). In this study of the working method we focus on the $3^{\text {rd }}$ Age.

The aim of this research is to test a working method for analyzing and improving Activities of Daily Living (ADL) for older persons in their $3^{\text {rd }}$ Age.

\section{Method}

A working method in this study is a set of coherent research activities to get insight and solutions for problematic ADLs.

The method is subdivided in two different tasks: (i) analyzing and (ii) improving a problematic ADL element. In spring 2009 three groups of international novice designers (MSc students in Architecture, Building Services and Human Technology Interaction) performed these two tasks as a part of a course in 'Robotics and Home Automation' under supervision of the first author. Before starting the tasks the students were instructed and did some exercises to become acquainted with the methodology. After the completion of the two tasks the student wrote a personal reflection on his/her learning experiences.

\section{Analyzing an ADL}

The instructions for the analysis task were:

1. Choose an ADL element, a suitable place to observe it in practice, and ask the subject if the group may do the analysis. Choose an activity that has something to do with mobility, and that is influenced by design and nature of the built environment.

2. Do a systematic literature search for the chosen ADL element to discover the most suitable methodology to describe and assess this activity. 
3. Describe the chosen ADL element after collecting the relevant information with photographs, videos, interviews, a process description (SADT), etc.

4. Analyze the data in a systematic way and draw conclusions. See Table 1 for an example of an analysis scheme.

5. Prepare your report with the following paragraphs: abstracts, introduction \& aim, methodology, results, discussion \& conclusions and references.

6. Prepare a poster and present and discuss it with fellow students and supervisors.

Table 1: Example of an analysis scheme

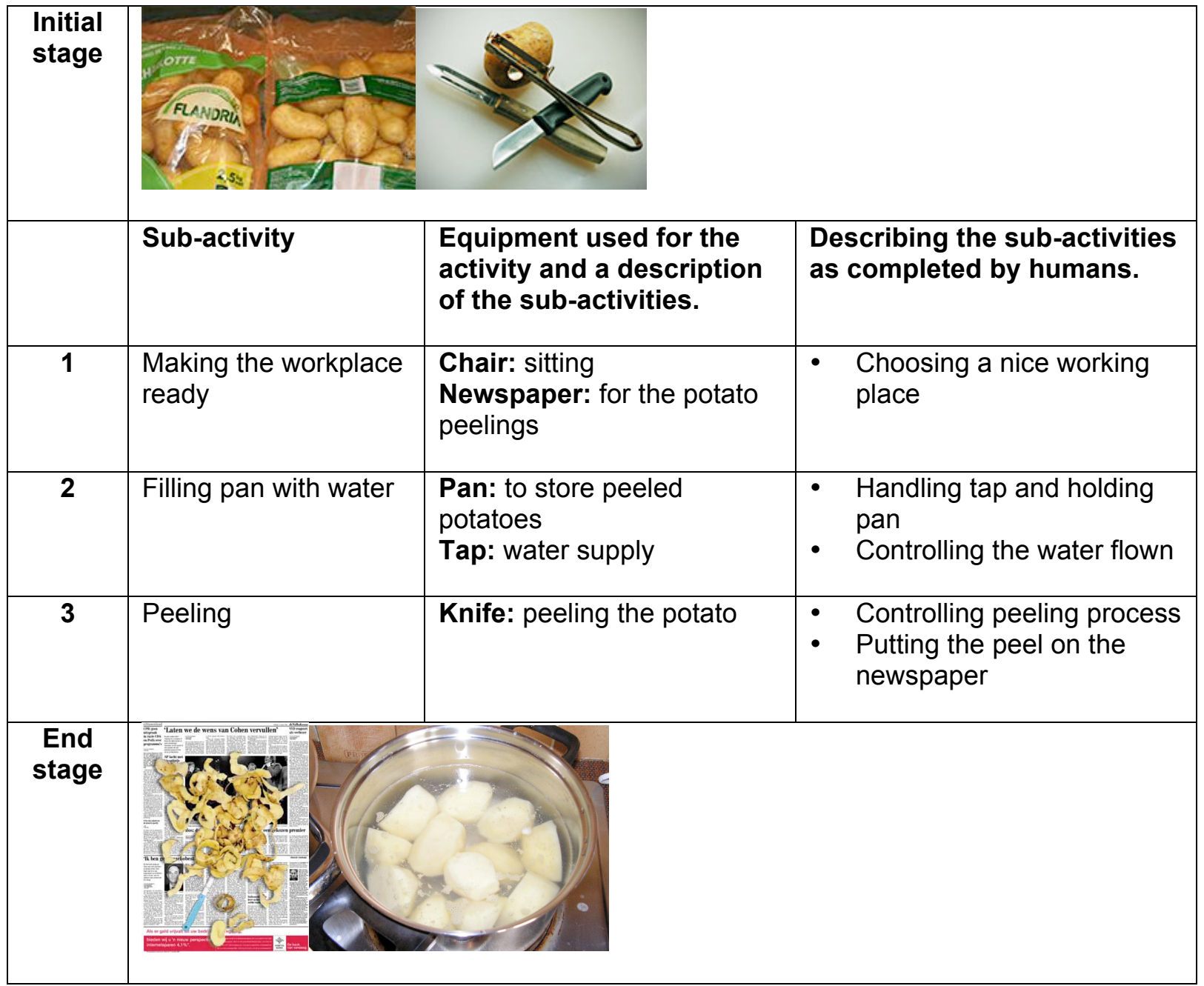

\section{Improving a problematic ADL}

The design of an improvement used principles of the morphological approach (Grant, 1984; Cross, 2008) and in particular the morphological matrix. In this matrix the vertical axis contains a description of functions, and the horizontal axis shows the possible ideas for each function. Each idea is obtained by using creativity techniques. An improvement is a series of possible ideas connected by a zigzag line (Figure 1). More lines may be drawn and the best line is chosen by contrasting them with the requirements. 


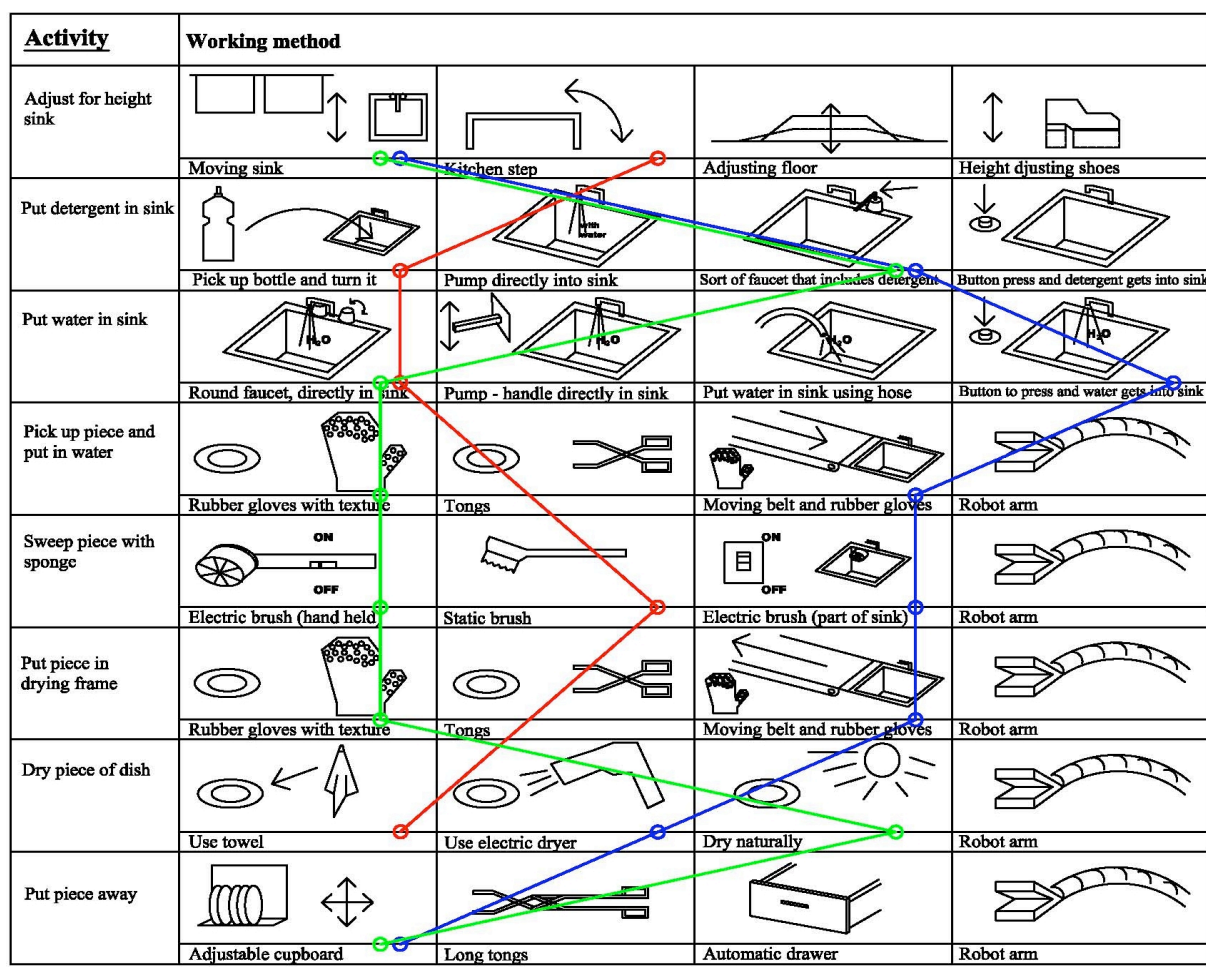

Figure 1: Morphological matrix filled with ideas and connected by zigzag lines (Cross, 2008).

The instructions for the improving tasks were follows:

1. Choose an aim to improve the problematic ADL element chosen by your group.

2. Describe and/or sketch the initial situation and the end situation of the ADL element.

3. Formulate characteristics of the initial and the end stage of the ADL element.

4. Formulate the requirements of improvement.

5. Draw a morphological matrix with sub-activities of a new ADL.

6. Create ideas for the sub-activities with the help of creativity techniques.

7. Draw in the scheme 2 or 3 zigzag lines which indicate a combination of ideas for the subactivities. The zigzag lines represent then the solutions.

8. Choose the best solution by contrasting them with the requirements.

9. Develop the best solution.

10. Write a group reflection about the solution.

11. Write a report with the following paragraphs: aim of the improvement, program of requirements, morphologic scheme and choice of best solution.

12. Prepare a PowerPoint presentation to evaluate the results with the other students and supervisors.

\section{Results}

The groups wrote a report for each task. In addition the results of the problem analyses and improvement were presented and discussed with the colleague students, the supervisor and experts. The results of the analyses are summarized in Table 2 and of the improvement in Table 3. 
Table 2. Analysis results

\begin{tabular}{|c|c|c|c|}
\hline & \multicolumn{3}{|c|}{ Student group } \\
\hline & $\mathbf{A}$ & B & C \\
\hline ADL chosen & Using buses and trains & Dish washing & Preparing food \\
\hline $\begin{array}{l}\text { Situation } \\
\text { chosen }\end{array}$ & $\begin{array}{l}\text { Railway station in } \\
\text { Eindhoven }\end{array}$ & Private apartment & $\begin{array}{l}\text { Private apartment and } \\
\text { assisted living facility }\end{array}$ \\
\hline $\begin{array}{l}\text { Research } \\
\text { objects }\end{array}$ & $\begin{array}{l}\text { Twelve older persons, } \\
\text { users of the public } \\
\text { transport }\end{array}$ & $\begin{array}{l}\text { Two older persons } \\
\text { (aged } 77 \text { and } 79 \text { years) }\end{array}$ & $\begin{array}{ll} & \text { Older woman living } \\
\text { alone } \\
\text { Older woman } \\
\text { temporarily living in } \\
\text { an assisted living } \\
\text { facility } \\
\end{array}$ \\
\hline $\begin{array}{l}\text { Problem } \\
\text { analyzing } \\
\text { results }\end{array}$ & $\begin{array}{l}\text { - Hard to get into the } \\
\text { train with luggage } \\
\text { - Rude fellow } \\
\text { passengers } \\
\text { - Rude bus drivers } \\
\text { The lift to the train } \\
\text { platform can only be } \\
\text { used with the help of } \\
\text { station staff }\end{array}$ & 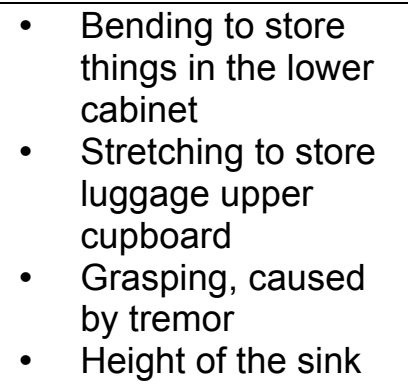 & $\begin{array}{ll} & \text { Mashing potatoes } \\
\text { - } & \text { Opening packaging } \\
\text { - } & \text { Pouring potatoes off } \\
& \text { food products in one } \\
\text { container }\end{array}$ \\
\hline
\end{tabular}

\section{Discussion}

All tasks have been completed by the groups and have resulted in an improvement of three problematic ADLs. The solutions were developed on a conceptual level, and have not been engineered nor checked in practice. Some improvements became known but not used in the situation of the tests.

Spending more time on the tasks and getting more experience with the working method will enhance the quality of the ADL improvement.

Feedback by future users will also improve the quality of the ADL supports (Lau and Franchimon 2009).

In the personal reflections on using the working method the students stated the following statements:

- "Very useful and broadly applicable";

- "To do observations make you real aware of the problem";

- "Some solutions already existed but not for this specific ADL";

- "The following steps in the method got our special attention: research, ideas, engineering and test; some steps are repeated";

- "Take time to formulate the problem and the solution";

- "You worked with more than one solution". 
Table 3: Results improvement

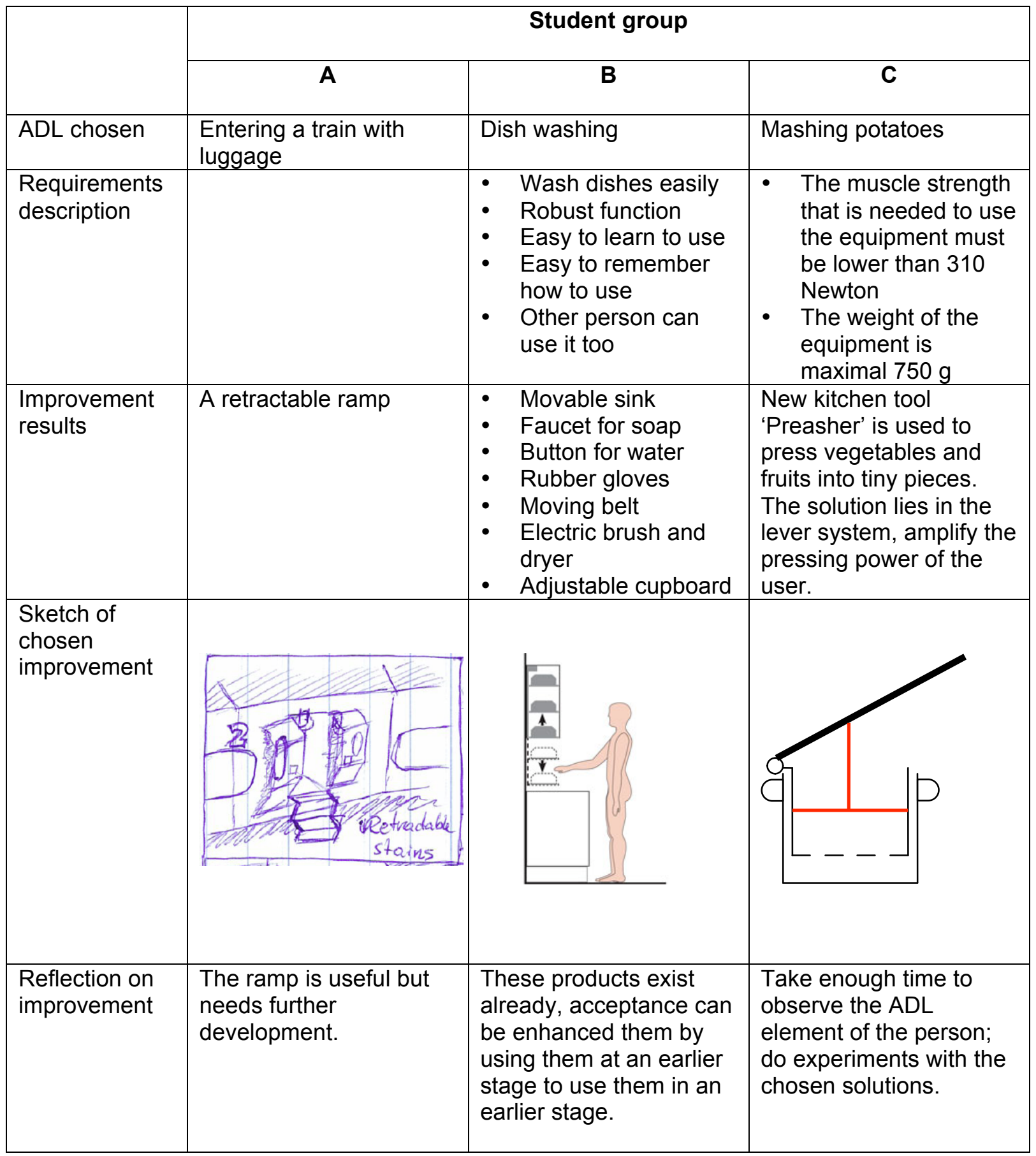

It is important for developers of new solutions to support problematic ADL to include specific competences in user-based design.

The aim of this research has been to test a working method for analyzing an element of an ADL, and to automate, robotize or mechanize it. Some elements of this working method appear to be essential for successfully improving the execution of problematic ADLs. An important addition will be producing prototypes en testing these with users. 


\section{Conclusions}

Our working method will decrease the gap between technology push and users pull.

The new information has already been successful in the world of user-oriented design, but is hardly used in the domain of built environments, particular in the domain of Aging-in-Place.

\section{Acknowledgements}

The authors thank the Architecture, Building Services and Human Technology Interaction students for their cooperation.

\section{References}

ADL http://en.wikipedia.org/wiki/Activities of daily living Observed 11th March 2010.

Bronswijk, JEMH van, 2009. Basics of Gerontechnology. Presentation at the International Conference on Gerontic Technology and Service Management. Nankai Institute of Technology, Tsaotun, Nantou, Taiwan.

Cross, N, 2008. Engineering Design Methods. John Wiley \& Sons Ltd.

Franchimon, F, 2009. Gezonde gebouwinstallaties voor de 21ste eeuw. Eindhoven University of Technology.

Grant, DP 1984. Creative idea production in architecture: the morphological approach. San Luis Obispo, California: The Design Methods Group.

Katz, S, TD Downs, HR Cash and RC Grotz,1970. Progress in Development of the Index of ADL. The Gerontologist10 (1 part 1): pp 20-30.

Lau, YY, C van't Hof and R van Est, 2009. Beyond the Surface. An Exploration in Healthcare Robotics in Japan. The Netherlands, The Hague, Rathenau Instituut TA Report.

Lawton, MP and EM Brody, 1969. Assessment of older people: Self-maintaining and instrumental activities of daily living. The Gerontologist 9: pp 179-186. 